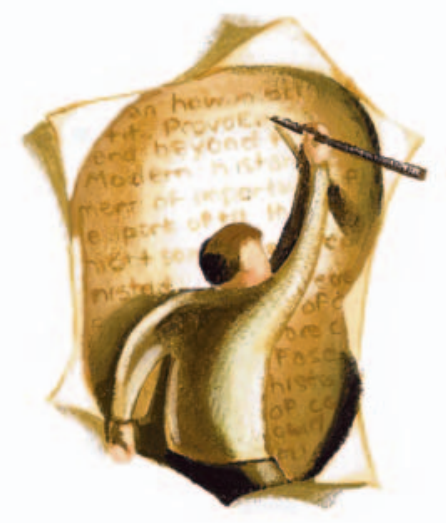

\section{Screening men}

\section{for osteoporosis}

I have many middle-aged and elderly men in my family practice, including some who are being treated for osteoporosis, and thus I read with interest the CMAJ article on managing osteoporosis in men by Aliya Khan and colleagues. ${ }^{1}$ I was surprised by the authors' statement that "as in the 2002 guidelines [from the Osteoporosis Society of Canada], [bone mineral testing] for all men over 65 is advised."

The article did not provide any evidence to support this recommendation, so I turned to the cited guidelines. ${ }^{2}$ The first sentence in the section on osteoporosis in men states that "there are insufficient data on the relation between [bone mineral density] and fracture risk in men." Neither the guidelines nor the article by Khan and colleagues provides information on the incidence of osteoporosis in men. It would seem to me that any further discussion should be postponed until such data are available. However, both documents go on to recommend screening for men over 65 years of age.

How can one propose screening for a disease when the incidence of the condition is unknown in the population in question and when use of the recommended screening tool cannot as yet be correlated with disease detection? Furthermore, no evidence was provided concerning the cost of screening, the number of cases of osteoporosis that would be diagnosed by screening all men (rather than only men at high risk of developing the disease) and the number of subsequent fractures that would be prevented by screening.

\section{Dara Behroozi MB BS \\ Clinical Associate Professor \\ Department of Family Practice \\ University of British Columbia \\ Vancouver, BC}

Competing interests: None declared.

\section{REFERENCES}

I. Khan A, Hodsman AB, Papaioannou A, et al. Management of osteoporosis in men: an update and case example. CMAJ 2007;176:345-8.

2. Brown JP, Josse RG; Scientific Advisory Council of the Osteoporosis Society of Canada. 2002 clinical practice guidelines for the diagnosis and management of osteoporosis in Canada [published errata in $C M A J$ 2003; $68: 400,2003 ; 168: 544$ and 2003; I68:676]. CMAJ 2002;167(Suppl Io):SI-34.

DOI:I0.I503/cmaj.I0700I8

\section{[The authors respond:]}

We thank Dara Behroozi for raising an important point concerning our article. ${ }^{1}$ Unfortunately, the data currently available on the cost-effectiveness of bone densitometry in men are very limited. Schousboe and colleagues recently evaluated the cost-effectiveness of bone densitometry followed by 5 years of oral bisphosphonate therapy to prevent fractures among older men with osteoporosis in the United States. ${ }^{2}$ They concluded that bone densitometry for all men as young as 70 years of age may be cost-effective. This assumes a societal willingness to pay US\$100 ooo per quality-adjusted life-year gained in addition to drug costs. The Osteoporosis Society of Canada's guidelines emphasize assessing key clinical risk factors for fracture (e.g., previous fracture history and glucocorticoid use) in conjunction with bone mineral density testing to determine treatment thresholds. ${ }^{3}$ In our article, we recommend targeting those at high risk of developing a fragility fracture for pharmacological intervention, which would improve the costeffectiveness of treatment.
On the basis of current expert opinion, the Osteoporosis Society of Canada's recommendations for bone mineral density testing and clinical risk factor assessment are appropriate. It is true that in the absence of a defining fracture event, a low bone mineral density alone places a man at less risk for fracture than a woman of similar age with a similar bone mineral density. White men at age 60 have a $29 \%$ risk of experiencing a fracture. ${ }^{4}$ One-third of all hip fractures occur in men; they are associated with equivalent morbidity and higher mortality compared with those occurring in women. ${ }^{5}$ Vertebral fractures are also associated with similar morbidity in men and women. ${ }^{6}$ More detailed Canadian studies will help to assess the cost-effectiveness of bone mineral density screening in men. The Osteoporosis Society of Canada is in the process of completing an exhaustive evidence-based review of osteoporosis in men, the results of which will be reflected in future guidelines.

\section{Aliya A. Khan MD}

Divisions of Endocrinology and

Geriatric Medicine

McMaster University

Oakville, Ont.

Anthony B. Hodsman MB BS

Divisions of Endocrinology and

Nephrology

University of Western Ontario

London, Ont.

Alexandra Papaioannou MSc MD

Division of Geriatric Medicine

McMaster University

Hamilton, Ont.

David Kendler MD

Division of Endocrinology

University of British Columbia

Vancouver, BC

Jacques P. Brown MD

Division of Rheumatology

Laval University

Québec City, Que.

Wojciech P. Olszynski MD PhD

Division of Rheumatology

University of Saskatchewan

Saskatoon, Sask.

Competing interests: None declared by Wojciech Olszynski. Aliya Khan has received consultancy fees, research grants and/or honoraria from 
Aventis-Sanofi, Merck, Eli Lilly, Novartis, NPS Allelix, Servier and Proctor \& Gamble. Anthony Hodsman has received consultancy fees, research grants and honoraria from Eli Lilly, Merck Frosst, NPS Allelix, Zelos Therapeutics, Servier, Proctor \& Gamble and Sanofi-Aventis. Alexandra Papaioannou has been a consultant to, has conducted clinical trials for and has received unrestricted grants from Eli Lilly, Merck Frosst, Procter \& Gamble and Aventis-Sanofi. She has also been a consultant to and has received unrestricted grants from Amgen and has conducted clinical trials for Novartis. David Kendler has served on the advisory board and speakers' bureau of and/or has received research grants from Alliance, Merck, Servier, Eli Lilly, Wyeth, Takeda, Zelos, Roche, Novartis and Pfizer. Jacques Brown has received consultancy and speaker's fees from Eli Lilly, Merck Frosst, Novartis, Sanofi-Aventis, Procter \& Gamble Pharmaceuticals, Amgen and Wyeth.

\section{REFERENCES}

I. Khan A, Hodsman AB, Papaioannou A, et al. Management of osteoporosis in men: an update and case example. CMAJ 2007; I76:345-8.

2. Schousboe JT, Taylor BC, Fink HA, et al. Costeffectiveness of bone densitometry followed by treatment of osteoporosis in older men. JAMA 2007;298:629-37.

3. Brown JP, Josse RG: Scientific Advisory Council of the Osteoporosis Society of Canada. 2002 clinical practice guidelines for the diagnosis and management of osteoporosis in Canada [published errata in $C M A J$ 2003; $68: 400,2003 ; 168: 544$ and 2003; I68:676]. CMAJ 2002;167(Suppl Io):SI-34.

4. Mussolino ME, Looker AC, Madans JH, et al. Risk factors for hip fracture in white men: the NHANES I Epidemiologic Follow-up Study. J Bone Miner Res I998;13:918-24.

5. Trombetti A, Herrmann F, Hoffmeyer P, et al. Survival and potential years of life lost after hip fracture in men and age-matched women. Osteoporos Int 2002;13:73I-7.

6. Jackson SA, Tenenhouse A, Robertson L. Vertebra fracture definition from population-based data: preliminary results from the Canadian Multicenter Osteoporosis Study (CaMos). Osteoporos Int 2000; 2:680-7.

DOI:I0.1503/cmaj.I070IIo

\section{Accuracy of point-of-care}

\section{measurements}

In a helpful case report in $C M A J$, Peter Brindley and colleagues reported falsely elevated lactate levels obtained with a point-of-care analyzer and low plasma lactate levels obtained with laboratory testing in a patient who had ingested ethylene glycol. ${ }^{1}$ Further investigation showed that the addition of even small amounts of glycolic acid or glyoxylic acid (the 2 predominant metabolites of ethylene glycol) to blood analyzed in the Radiometer ABL 700 point-of-care analyzer resulted in a marked artifactual elevation in lactate levels. Such elevations were not seen with the other analyzers tested (including the Vitros laboratory analyzer).

We recently reported a comparable observation in a man who accidentally ingested a large amount of propylene glycol. ${ }^{2}$ Arterial blood gas analysis with the Radiometer $\mathrm{ABL} 700$ point-of-care analyzer showed a very high concentration of lactate (up to $39 \mathrm{mmol} / \mathrm{L}$ ), but a normal reading was obtained with the Vitros laboratory analyzer. However, in our case the falsely elevated reading with the point-of-care analyzer was not caused by any interference with propylene glycol or its metabolites. Analysis with a sensitive and specific D-lactate kit revealed the presence of a very high amount (more than $100 \mathrm{mmol} / \mathrm{L}$ ) of Dlactate but not $\mathrm{L}$-lactate. Interference in this case was apparently due to the intestinal conversion of the orally ingested propylene glycol into D-lactate, which was erroneously measured as Llactate by the point-of-care analyzer.
The key objective of point-of-care testing is to generate a result quickly so that appropriate treatment can be implemented, leading to an improved clinical or economic outcome. These 2 cases show that it is crucial, especially in patients intoxicated with glycols, to confirm extreme point-of-care results with laboratory testing.

\section{Philippe G. Jorens MD PhD Department of Critical Care Medicine Antwerp University Hospital Edegem, Belgium}

Competing interests: None declared.

\section{REFERENCES}

I. Brindley PG, Butler MS, Cembrowski G, et al. Falsely elevated point-of-care lactate measurement after ingestion of ethylene glycol. CMAJ 2007;176: Iog7-9.

2. Jorens PG, Demey HE, Schepens PJC, et al. Unusual D-lactic acid acidosis from propylene glycol metabolism in overdose. J Toxicol Clin Toxico 2004;42:163-9.

DOI:I0.I503/cmaj.I070II3

\section{Letters submission process}

CMAJ's enhanced letters feature is now the portal for all submissions to our letters column. To prepare a letter, visit www.cmaj.ca and click "Submit a response to this article" in the box near the top right-hand corner of any CMAJ article. All letters will be considered for publication in the print journal.

Letters written in response to an article published in $C M A J$ are more likely to be accepted for print publication if they are submitted within 2 months of the article's publication date. Letters accepted for print publication are edited for length (usually 250 words) and house style.

\section{Mécanisme de présentation des lettres}

Le site amélioré des lettres du JAMC est désormais le portail de réception de tous les textes destinés à la chronique Lettres. Pour rédiger une lettre, consultez un article sur le site www.jamc.ca et cliquez ensuite sur le lien «Lettres électroniques : répondre à cet article», dans la boîte en haut à droite de l'article. Toutes les lettres seront étudiées pour une éventuelle publication dans le journal imprimé.

Les lettres répondant à un article publié dans le $J A M C$ sont plus susceptibles d'être acceptées pour publication imprimée si elles sont présentées dans les deux mois de la date de publication de l'article. Les lettres acceptées pour publication imprimée sont révisées en fonction du style du JAMC et raccourcies au besoin (elles doivent habituellement compter au maximum 250 mots). 